\title{
Article
}

\section{Optimal Hybridization of Conventional ICE Vehicles}

\author{
Zhemin Hu, Ramin Tafazzoli Mehrjardi $\mathbb{D}_{\text {, Lin Lai and Mehrdad Ehsani * }}$
}

Department of Electrical Engineering, Texas A\&M University, College Station, TX 77840, USA; zhemin37@tamu.edu (Z.H.); ramin.tafazzoli@tamu.edu (R.T.M.); lailinabc@gmail.com (L.L.)

* Correspondence: ehsani@ece.tamu.edu; Tel.: +1-979-845-7582

check for updates

Citation: Hu, Z.; Mehrjardi, R.T.; Lai, L.; Ehsani, M. Optimal Hybridization of Conventional ICE Vehicles. Eng 2021, 2, 592-607. https://doi.org/ 10.3390/eng2040037

Academic Editor: Antonio Gil Bravo

Received: 6 August 2021

Accepted: 5 November 2021

Published: 12 November 2021

Publisher's Note: MDPI stays neutral with regard to jurisdictional claims in published maps and institutional affiliations.

Copyright: (c) 2021 by the authors. Licensee MDPI, Basel, Switzerland. This article is an open access article distributed under the terms and conditions of the Creative Commons Attribution (CC BY) license (https:/ / creativecommons.org/licenses/by/ $4.0 /)$.

\begin{abstract}
Most commercially available hybrid electric vehicle (HEV) drivetrains are made of small internal combustion (IC) engines and large electric drives to improve fuel economy. They usually have higher cost than the conventional IC-engine-based vehicles because of the high costs of the electric drives. This paper proposes a hybridized powertrain composed of the original full-size engine of the vehicle and a universally optimum size parallel electric drive. The dynamic programming (DP) algorithm was used to obtain the sensitivity of the maximum miles per gallon (MPG) values versus the power rating of the electric drive. This sensitivity was then analyzed to determine the optimal window of the electric drive power ratings. This was proven to be universal for all passenger cars of various masses and engine powers. The fuel economy and vehicle performance of this HEV was compared with those of the 2019 Toyota Corolla, a conventional IC-engine-based vehicle, and the 2019 Toyota Prius, a commercially available HEV. The results showed that the proposed universally optimized HEV powertrain achieved better fuel economy and vehicle performance than both the original ICE and HEV vehicles, at low additional vehicle cost.
\end{abstract}

Keywords: fuel optimization; low cost HEV; optimum hybridization

\section{Introduction}

Conventional vehicles, powered by internal combustion (IC) engines, are a major source of carbon dioxide emission, causing global warming [1]. They also pollute the air with significant emissions of toxic gases such as nitrogen oxides (NOx), carbon monoxide (CO), and unburned hydrocarbons [1]. Another drawback of the IC engine is its low efficiency. Its typical efficiency is around $20 \%$ which is much lower than an electric motor whose efficiency is around $85 \%$ [2]. This low efficiency leads to the poor fuel economy of IC engine based vehicles, especially in urban driving cycles.

It is now known that electric vehicles (EV) have certain advantages over IC engine based vehicles, such as higher efficiency, no tailpipe emissions, smoother operation and less noise [1]. However, they also have several disadvantages, such as short travel range, long battery recharging time, and high comparative costs. For example, the 2020 Chevrolet Bolt, a commercially available EV, can have an additional travel range of only 90 miles after its battery is recharged for $30 \mathrm{~min}$ at a Level 3 charging station [3]. This time is much longer than the time needed for filling a gasoline tank [2]. In addition, the travel range of EV can be even shorter under lower ambient temperatures. For instance, it can be shown that the travel distance of the Mitsubishi i-MiEV, a commercial EV, decreases at a rate of $2.5 \mathrm{~km}$ per $1{ }^{\circ} \mathrm{C}$ temperature drop in the ambient temperature range of $+20^{\circ} \mathrm{C}$ to $-15^{\circ} \mathrm{C}$ [4]. Furthermore, the electric drive and battery in the EV have a significantly higher total cost than an IC engine and its gasoline tank, leading to a higher cost for the EV.

To combine the advantages of the IC engine based vehicle and the EV, the hybrid electric vehicle (HEV) typically contains an IC engine to deliver the average tractive power and an electric motor to supply the peak power. In this way, the power rating of the IC engine can be reduced to less than half of that in an equivalent conventional vehicle with the same mass and dynamic specifications $[1,5]$. However, the HEV must use this 
small IC engine alone if the state of charge (SOC) of the battery drops to its lower limit, negatively affecting the vehicle performance. In addition, due to its large electric drive and battery bank, the cost of the HEV is usually much higher than its equivalent conventional vehicle. Although the fuel economy is improved in such $\mathrm{HEV}$, the cost savings on the fuel consumption cannot offset its high initial cost in a reasonable time period. For instance, it can be shown that the Toyota Prius, a conventional HEV, has a cost payback mileage of about 150,600 miles which is close to the vehicle's lifespan [2]. Furthermore, control strategies for HEV powertrains usually have to be adjusted according to different driving conditions [6,7]. For these reasons, the market share of HEVs in the US has remained small over the past two decades. To further improve the fuel economy, plug-in hybrid electric vehicles (PHEV) were introduced. These use even larger battery banks with energy capacity of over $4 \mathrm{kWh}$ and large electric drives to supply adequate power for pure electric drive [8]. In the PHEV, more of the gasoline energy is replaced with the battery energy, obtained from the power grid [9]. Thus, the fuel economy of the PHEV can be increased to 95 miles per gallon (MPG) while in its pure electric range of about 37 miles [10]. However, the MPG value of the PHEV will drop to the same level as that of Toyota Prius when traveling beyond this pure electric range. In the meantime, the PHEV has two times larger battery bank, which significantly raises its cost, with a payback mileage as long as 117,600 miles even with the highest 95 MPG [2]. Reference [11] shows that the PHEV can only bring a fuel savings of $\$ 10$ to $\$ 120$ annually, which cannot offset its high cost in a short term.

To overcome the drawbacks of the conventional HEVs and PHEVs, this paper proposes a new approach to HEV drivetrain design. The new design approach keeps the full-size engine as the primary vehicle power plant, with its associated longer travel range, better performance and much higher energy density of the fossil, compared to batteries. The full-size engine is defined as an engine that has the capability of propelling the vehicle alone during typical driving conditions. Then, a relatively small electric drive is added in parallel with this full-size engine to optimally improve the fuel economy and vehicle performance, beyond the IC engine alone. Here, the additional cost and mass of the electric drive will be offset by the savings in fuel economy improvement. For this, the optimal window of the electric drive power ratings, in which the fuel economy is maximized, has to be determined. This paper presents the results of this optimization using the dynamic programming (DP) algorithm to analyze the sensitivity of the fuel consumption to the electric drive power ratings. The sensitivity analysis was applied to hybridization of three conventional vehicles with different IC engine power ratings and different vehicle masses in order to demonstrate that the optimal window of the electric drive power ratings is applicable to all common types of passenger cars. This means all sizes of conventional IC engine vehicles can be optimally hybridized by a specific electric drive power rating in the optimal window. This universally sized electric drive package can potentially reduce the production costs of the electric drives in all full-size engine HEVs. To illustrate the advantages of these HEVs over the conventional IC engine vehicles and commercially available HEVs, their vehicle performances, fuel economies and the payback mileages were compared.

\section{Basic Structure of a Full-Size Engine HEV}

The full-size engine has been used in a commercially available vehicle propelled solely by the IC engine (hereinafter called an IC engine vehicle). It has been commercially proven to have the capability of propelling the vehicle alone during all common driving conditions. This paper will take three typical IC engine vehicles, Toyota Corolla 2019, Toyota Camry 2016, and Chrysler 300 2016, as examples to demonstrate the transformation of IC engine vehicles into full-size engine HEVs by adding a small electric drive in parallel with the full-size engine of the IC engine vehicles. The three IC engine vehicles have different curb masses and IC engine power ratings, as shown in Table 1, which can represent compact, medium-sized and large-sized passenger cars on the market. 
The drivetrain configuration of a torque-coupling parallel HEV with a full-size engine is shown in Figure 1. It contains two power plants, an IC engine and an electric motor. The engine is connected to a torque-coupler via a multi-gear transmission, and the motor is connected to the same torque-coupler via a single-gear transmission. The torque-coupler enables the torque on the driving shaft to be equal to the sum of the torques on the engine shaft and the motor shaft, whereas the speed of the driving shaft is proportional to the speeds of both the engine shaft and the motor shaft. A final drive is used to distribute the driving shaft torque to each driving wheel through a differential. The load power on the driving wheels, $P_{l}$, has a relation with powers of engine and motor expressed as

$$
P_{1}=P_{e_{-} w}+P_{m \_} w,
$$

where $P_{e_{-} w}$ and $P_{m_{-} w}$ are the engine power and the motor power transmitted onto the driving wheels, respectively.

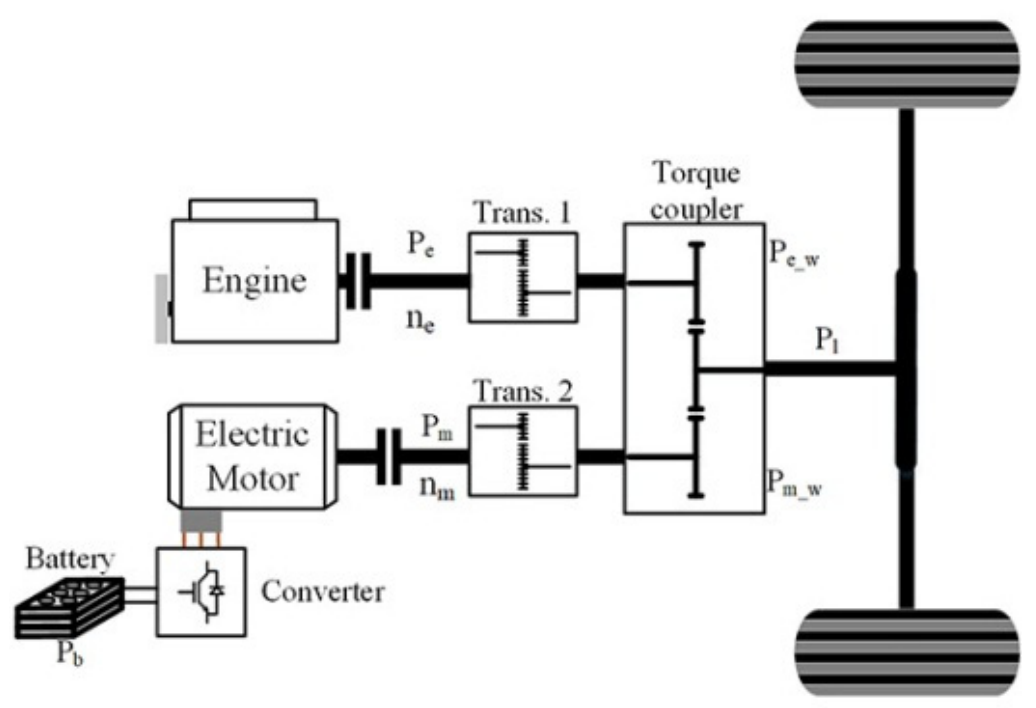

Figure 1. Drivetrain configuration of a torque-coupling parallel HEV. Adapted from Ref. [2].

The parameters of the three IC engine vehicles and of the designed motors used in this study are listed in Tables 1 and 2, where $\delta_{1}$ and $\delta_{2}$ are used to calculate the rotational inertia factor which converts the inertia of all rotating components to the equivalent mass and can be expressed as

$$
\delta=1+\delta_{1}+\delta_{2} i_{0}^{2}\left(i_{g e}^{2}+i_{g m}^{2}\right)
$$

where, $i_{g e}$ and $i_{g m}$ are the gear ratios of the transmissions connected to the engine and the motor, respectively, and $i_{0}$ is the gear ratio of the final drive. For an eight-gear transmission, $i_{g e}$ can be any one of the eight gear ratios of the engine transmission listed in Table 1, depending on which gear is used at a time. To demonstrate the universality associated with the power rating of the electric drive (discussed later in Section 4), the motor parameters in Table 2 are designed to be the same for all the three IC engine vehicles, except $i_{g m}$ which is designed to keep the product of $i_{g m}$ and $i_{0}$ the same for all the three IC engine vehicles. 
Table 1. Vehicle parameters of 3 typical IC engine vehicles [1,2,12-14].

\begin{tabular}{|c|c|c|c|}
\hline Vehicle & Toyota Corolla 2019 & Toyota Camry 2016 & Chrysler 3002016 \\
\hline Curb mass $(M)$ & $1285 \mathrm{~kg}$ & $1497 \mathrm{~kg}$ & $1828 \mathrm{~kg}$ \\
\hline IC engine power rating $\left(P_{\text {erated }}\right)$ & $98 \mathrm{~kW}$ & $133 \mathrm{~kW}$ & $218 \mathrm{~kW}$ \\
\hline Number of transmission gears & 6 & 6 & 8 \\
\hline 1st gear ratio $\left(i_{g e 1}\right)$ & 3.54 & 3.3 & 4.71 \\
\hline 2nd gear ratio $\left(i_{g e 2}\right)$ & 1.91 & 1.9 & 3.14 \\
\hline 3rd gear ratio $\left(i_{g e 3}\right)$ & 1.31 & 1.42 & 2.1 \\
\hline 4 th gear ratio $\left(i_{g e 4}\right)$ & 0.97 & 1 & 1.67 \\
\hline 5 th gear ratio $\left(i_{g e 5}\right)$ & 0.71 & 0.713 & 1.29 \\
\hline 6 th gear ratio $\left(i_{g e 6}\right)$ & 0.62 & 0.608 & 1 \\
\hline 7 th gear ratio $\left(i_{g e 7}\right)$ & - & - & 0.84 \\
\hline 8th gear ratio $\left(i_{g e 8}\right)$ & - & - & 0.67 \\
\hline Gear ratio of final drive $\left(i_{0}\right)$ & 4.21 & 3.634 & 2.62 \\
\hline Gravitational acceleration $(g)$ & 9.8 & 9.8 & 9.8 \\
\hline Rolling resistance coefficient $\left(f_{r}\right)$ & 0.01 & 0.01 & 0.01 \\
\hline Air density $\left(\rho_{a}\right)$ & $1.205 \mathrm{~kg} / \mathrm{m}^{3}$ & $1.205 \mathrm{~kg} / \mathrm{m}^{3}$ & $1.205 \mathrm{~kg} / \mathrm{m}^{3}$ \\
\hline Frontal area $\left(A_{f}\right)$ & $2.2 \mathrm{~m}^{2}$ & $2.3 \mathrm{~m}^{2}$ & $2.4 \mathrm{~m}^{2}$ \\
\hline Aerodynamic drag coefficient $\left(C_{D}\right)$ & 0.3 & 0.3 & 0.3 \\
\hline Wheel radius $\left(r_{d}\right)$ & $0.31 \mathrm{~m}$ & $0.33 \mathrm{~m}$ & $0.36 \mathrm{~m}$ \\
\hline Wheel mass factor $\left(\delta_{1}\right)$ & 0.04 & 0.04 & 0.04 \\
\hline Power plant rotor mass factor $\left(\delta_{2}\right)$ & 0.0025 & 0.0025 & 0.0025 \\
\hline $\begin{array}{c}\text { Transmission efficiency from engine to } \\
\text { driving wheels }\left(\eta_{t, e}\right)\end{array}$ & 0.9 & 0.9 & 0.9 \\
\hline
\end{tabular}

Table 2. Parameters of designed electric motors for hybridization of three typical IC engine vehicles.

\begin{tabular}{cccc}
\hline Vehicle & Toyota Corolla 2019 & Toyota Camry 2016 & Chrysler 300 2016 \\
\hline Maximum speed of motor $\left(n_{m \max }\right)$ & $6000 \mathrm{rpm}$ & $6000 \mathrm{rpm}$ & $6000 \mathrm{rpm}$ \\
Base speed of motor $\left(n_{m \mathrm{~b}}\right)$ & $1500 \mathrm{rpm}$ & $1500 \mathrm{rpm}$ & $1500 \mathrm{rpm}$ \\
Gear ratio of motor transmission $\left(i_{g m}\right)$ & 1.48 & 1.72 & 2.39 \\
Power efficiency of motor $\left(\eta_{m}\right)$ & 0.88 & 0.88 & 0.88 \\
Transmission efficiency from motor to & 0.95 & 0.95 & 0.95 \\
driving wheels $\left(\eta_{t, m}\right)$ & & \\
\hline
\end{tabular}

The mechanical resistances opposing the vehicle movement consist of rolling resistance, aerodynamic drag, and grading resistance. Taking the vehicle acceleration into consideration, we can express the load power $P_{l}$ as

$$
P_{l}=V\left(M g f_{r}+\frac{1}{2} \rho_{a} C_{D} A_{f} V^{2}+M g i\right)+M \delta V \frac{d V}{d t}
$$

where, $V$ is the vehicle speed, and $i$ is the road grade.

The electric drive consists of the motor, power electronic converters, and a battery pack. The maximum torque of the motor is constant when the motor speed is below the base speed, whereas the maximum power of the motor is constant when the motor speed is above the base speed. That is, the motor has nearly ideal torque-speed and power-speed profiles. Therefore, only a single-gear transmission is needed for the motor. The widely used battery packs for HEVs and EVs are nickel metal hydride (NiMH) batteries and Li-ion batteries [15]. Research in [16-19] shows that the energy density and efficiency of Li-ion batteries are significantly higher than those of NiMH batteries. Hence, the Li-ion battery pack is used here to deliver electrical power to the motor. The total mass of the electric drive should be considered during the optimization process of the electric drive power rating because it has an adverse effect on the fuel economy of the HEV. We assume that motors with power ratings from $3 \mathrm{~kW}$ to $40 \mathrm{~kW}$ have a constant mass per $\mathrm{kW}$ factor which is $2.5 \mathrm{in}$ this paper. We also assume that the specific power of the battery pack is $1.28 \mathrm{~kW} / \mathrm{kg}$, and 
the energy / power ratio of the battery pack is $0.03 \mathrm{~h}$. Based on these assumptions, the masses of electric drives with various power ratings from $3 \mathrm{~kW}$ to $45 \mathrm{~kW}$ are estimated and listed in Table 3.

Table 3. Mass estimation of the electric drives. Adapted from Ref. [2].

\begin{tabular}{cc}
\hline Electric Drive Power Rating $\mathbf{( k W )}$ & Mass $\mathbf{( k g )}$ \\
\hline 45 & 147 \\
40 & 130 \\
35 & 114.5 \\
30 & 99 \\
25 & 82.5 \\
20 & 66.3 \\
15 & 49.8 \\
10 & 33.3 \\
5 & 16.8 \\
3 & 10.6 \\
\hline
\end{tabular}

\section{Dynamic Programming Algorithm in HEV}

The dynamic programming (DP) algorithm optimizes a cost function and finds the optimal sequences of control variables in the whole process by making control decisions, step-by-step, in time domain [20,21]. The cost function in HEV drivetrain control is the total fuel consumption of the engine during a certain driving cycle.

Research in $[5,22]$ uses the DP algorithm whose control variable is the output power or torque of the engine. This algorithm will either lead to the depletion of the battery or select the pure electric mode for only a short distance and switch to the engine-alone mode after the battery SOC drops to its lower bound, which is not an optimal control for an HEV. Although this situation can be avoided by adding electric energy usage penalties (i.e., electric penalties) to the cost function, the weights of the gasoline usage cost and the electric penalties will highly affect the control sequences, leading to the non-optimality of the obtained solution.

To overcome the disadvantages of algorithms applied in previous research, the DP algorithm used in this paper selects the battery SOC as well as the number of gears of the engine transmission as the control variables. This selection can avoid battery depletion without adding the electric penalties, and thus the optimality of the obtained solution is guaranteed. In this algorithm, the output powers of the engine and the motor are calculated according to the battery SOCs, $\operatorname{SOC}(k)$ and $\operatorname{SOC}(k+1)$, at two adjacent time steps, $k$ and $k+1$, in a driving cycle. If $\operatorname{SOC}(k)>\operatorname{SOC}(k+1)$, the battery is discharged, and the motor power on the driving wheels is expressed as

$$
P_{m_{-} w}=\frac{(\operatorname{SOC}(k)-\operatorname{SOC}(k+1)) Q_{n} \eta_{b_{-} w}}{\Delta t}
$$

where $Q_{n}$ is the battery energy capacity, $\eta_{b_{-} w}$ is the power efficiency from the battery to the driving wheels, and $\Delta t$ is the time interval between time steps $k$ and $k+1$. Otherwise, the battery is charged if $\operatorname{SOC}(k)<\operatorname{SOC}(k+1)$, and the motor power on the driving wheels is expressed as

$$
P_{m_{-} w}=\frac{(\operatorname{SOC}(k)-\operatorname{SOC}(k+1)) Q_{n}}{\eta_{w_{-} b} \Delta t}
$$

where $\eta_{w_{-} b}$ is the power efficiency from the driving wheels to the battery. If $\operatorname{SOC}(k)=\operatorname{SOC}(k+1)$, there is no energy delivered from or to the battery, and thus $P_{m_{-} w}=0$. The battery energy capacity, $Q_{n}$, is related to the output power rating of the electric drive, $P_{m_{-} \text {rated }}$, which is expressed as

$$
Q_{n}=\frac{P_{m \_r a t e d} R_{e / p}}{\eta_{m}}
$$

where, $R_{e / p}$ is the energy/power ratio of the battery and is assumed to be $0.03 \mathrm{~h}$ in this paper. 
Using (1), the engine power on the driving wheels, $P_{e_{-} w}$, can also be calculated, with the load power, $P_{l}$, obtained from the driving cycle as expressed in (3). The output power, $P_{e}$, and speed, $n_{e}$, of the engine on its own shaft are calculated as

$$
\begin{gathered}
P_{e}=\frac{P_{e_{-} w}}{\eta_{t, e}} \\
n_{e}=\frac{30 i_{g e} i_{0} V}{\pi r_{d}}
\end{gathered}
$$

where, $i_{g e}$ is determined by the gear number of the engine transmission, as shown in Table 1.

The fuel consumption, $F_{c}$, in the time interval $\Delta t$ is calculated as

$$
F_{c}=\frac{P_{e} g_{e} \Delta t}{\rho_{f}}
$$

where $\rho_{f}$ is the mass density of gasoline, which is assumed to be $0.75 \mathrm{~kg} / \mathrm{L}$ in this paper, and $g_{e}$ is the brake specific fuel consumption (BSFC) of the engine, which is determined by $P_{e}$ and $n_{e}$ in the engine fuel consumption map.

Suppose the driving cycle has $N+1$ discrete time steps from time step 0 to time step $N$. Because the engine delivers the average tractive power and the motor only supplies the peak power, all the net energy used during the entire driving cycle is only delivered by the engine. Therefore, the battery SOC must be the same value, $\mathrm{SOC}_{\text {init, }}$ at both time steps 0 and $N$. At each of other time steps, the battery SOC can be any value within its full usable range, $\mathrm{SOC}_{\min } \leq \mathrm{SOC} \leq \mathrm{SOC}_{\max }$. Suppose the range is discretized into $i_{m}$ values, that is,

$$
\mathrm{SOC}_{\text {min }}=\mathrm{SOC}_{1}<\mathrm{SOC}_{2}<\ldots<\mathrm{SOC}_{i_{m}}=\mathrm{SOC}_{\max }
$$

Suppose the value of the battery SOC is $\mathrm{SOC}_{i}$ at time step $k$ and $\mathrm{SOC}_{r}$ at time step $k+1$, where $\mathrm{SOC}_{i}$ and $\mathrm{SOC}_{r}$ are within the SOC range, $1 \leq i, r \leq i_{m}$, and $1 \leq k \leq N-2$. Suppose the $j$ th gear of the engine transmission, $\mathrm{G}_{j}$, is selected at time step $k$, where $1 \leq j \leq j_{m}$, and $j_{m}=6$ for a six-gear transmission. For the time interval $\Delta t_{k}$ from time step $k$ to time step $k+1$, we have a recursive relation of fuel consumption expressed as

$$
J^{*} \operatorname{SOC}_{r}(k+1)=\min _{1 \leq i \leq i_{m}}\left\{\min _{1 \leq j \leq j_{m}}\left[F_{\mathcal{C}}\left(\operatorname{SOC}_{i, r}(k), \mathrm{G}_{j}(k)\right)\right]+J^{*} \operatorname{SOC}_{i}(k)\right\}
$$

where $J^{*} \operatorname{SOC}_{i}(k)$ and $J^{*} \mathrm{SOC}_{r}(k+1)$ are the minimum total fuel consumptions from time step 0 to time step $k$ with $\mathrm{SOC}_{i}$ at time step $k$ and from time step 0 to time step $k+1$ with $\mathrm{SOC}_{r}$ at time step $k+1$, respectively, and $F_{c}\left(\mathrm{SOC}_{i, r}(k), \mathrm{G}_{j}(k)\right)$ is the fuel consumption in the time interval $\Delta t_{k}$ with $\mathrm{SOC}_{i}$ at time step $k, \mathrm{SOC}_{r}$ at time step $k+1$, and the $j$ th gear selected at time step $k$. Using (11), we can obtain the minimum total fuel consumption from time step 0 to time step $k+1$ for every $\mathrm{SOC}_{r}$ within $\mathrm{SOC}_{\min } \leq \mathrm{SOC}_{r} \leq \mathrm{SOC}_{\max }$ at time step $k+1$ and every $k$ within $1 \leq k \leq N-2$.

In the initial time interval $\Delta t_{0}$ from time step 0 to time step 1 and the terminal time interval $\Delta t_{N-1}$ from time step $N-1$ to time step $N$, the recursive relations of fuel consumption are expressed as

$$
\begin{gathered}
J^{*} \operatorname{SOC}_{r}(1)=\min _{1 \leq j \leq j_{m}}\left[F_{\mathcal{C}}\left(\operatorname{SOC}_{\text {init }, r}(0), \mathrm{G}_{j}(0)\right)\right]+J^{*} \operatorname{SOC}_{\text {init }}(0) \\
J^{*} \operatorname{SOC}_{\text {init }}(N)=\min _{1 \leq i \leq i_{m}}\left\{\min _{1 \leq j \leq j_{m}}\left[F_{\mathcal{C}}\left(\operatorname{SOC}_{i, \text { init }}(N-1), \mathrm{G}_{j}(N-1)\right)\right]+J^{*} \operatorname{SOC}_{i}(N-1)\right\}
\end{gathered}
$$

where, $F_{\mathcal{c}}\left(\mathrm{SOC}_{\text {init }, r}(0), \mathrm{G}_{j}(0)\right)$ is the fuel consumption in the time interval $\Delta t_{0}$ with $\mathrm{SOC}_{r}$ at time step 1 and the $j$ th gear selected at time step $0, F_{\mathcal{C}}\left(\mathrm{SOC}_{i, \text { init }}(N-1), \mathrm{G}_{j}(N-1)\right)$ is the fuel consumption in the time interval $\Delta t_{N-1}$ with $\mathrm{SOC}_{i}$ at time step $N-1$ and the jth gear 
selected at time step $N-1$, and $J^{*}{ }^{5 O C} C_{\text {init }}(N)$ is the minimum total fuel consumption during the entire driving cycle. The initial fuel consumption at time $0, J^{*}{ }{ } C_{\text {init }}(0)$, is assumed to be zero. Using (12), the minimum total fuel consumption from time step 0 to time step $1, J^{*} \mathrm{SOC}_{r}(1)$, is obtained for every $\mathrm{SOC}_{r}$ within $\mathrm{SOC}_{\min } \leq \mathrm{SOC}_{r} \leq \mathrm{SOC}_{\max }$ at time step 1 , whereas $J^{*} \operatorname{SOC}_{\text {init }}(N)$ obtained in (13) is a unique value solely for the single initial and terminal SOC value, $\mathrm{SOC}_{\text {init, }}$ which is also within the SOC usable range.

Using (1)-(3) and (4)-(9), we can obtain $P_{e_{-} w}, P_{m_{-} w}$ and $F_{c}$ in every time interval $\Delta t_{k}$ for every set of $\mathrm{SOC}_{i}(k), \mathrm{SOC}_{r}(k+1)$ and $\mathrm{G}_{j}(k)$ values. However, not all of the discrete values within the SOC usable range can be assigned to $\mathrm{SOC}_{i}$ and $\mathrm{SOC}_{r}$ in practical conditions because $P_{e_{-} w}$ and $P_{m_{-} w}$ must satisfy the following constraint conditions expressed as

$$
\begin{gathered}
P_{m \_ \text {min }}\left(n_{m}(k)\right) \leq P_{m \_w}(k) \leq P_{m \_ \text {max }}\left(n_{m}(k)\right) \\
P_{e_{-} \min }\left(n_{e}(k)\right) \leq P_{e_{\_} w}(k) \leq P_{e_{-} \max }\left(n_{e}(k)\right) .
\end{gathered}
$$

where the upper and lower bounds of $P_{e_{-} w}$ and $P_{m_{-} w}$ are functions of the engine speed, $n_{e}(k)$, and the motor speed, $n_{m}(k)$, respectively. The functions are determined by the power ratings and the power-speed characteristics of the engine and the motor. Every set of $\mathrm{SOC}_{i}(k)$, $\mathrm{SOC}_{r}(k+1)$ and $\mathrm{G}_{j}(k)$ values which cause $P_{e_{-} w}$ or $P_{m \_} w$ to go beyond the corresponding constraint condition in (14) or (15) should be excluded from the optimization processes expressed in (11)-(13).

Besides the final minimum value of the cost function, $J^{*} \operatorname{SOC}_{\text {init }}(N)$, we can also obtain the optimal values of $\operatorname{SOC}_{i}(k)$ and $\mathrm{G}_{j}(k)$ that lead to $J^{*} \operatorname{SOC}_{\text {init }}(N)$ with $k=N-1$ from (13). Then, with $k=N-2$, we let $\mathrm{SOC}_{r}(k+1)$ be equal to the optimal value of $\mathrm{SOC}_{i}(N-1)$ and use (11) to find the optimal values of $\mathrm{SOC}_{i}(k)$ and $\mathrm{G}_{j}(k)$. Repeat this with $k=N-3, N-4, \ldots$, 1. Finally, substituting the optimal value of $\mathrm{SOC}_{r}(1)=\mathrm{SOC}_{i}(1)$ into (14), we obtain the optimal value of $\mathrm{G}_{j}(0)$. Letting $\mathrm{G}_{j}(N)=\mathrm{G}_{j}(0)$ and $\operatorname{SOC}_{i}(N)=\mathrm{SOC}_{i}(0)=\mathrm{SOC}_{\text {init }}$, we obtain the optimal sequences of the control variables, $\mathrm{SOC}_{i}(k)$ and $\mathrm{G}_{j}(k)$ with $k=0,1, \ldots, N$. Using (1)-(3) and (4)-(8), we can also obtain the optimal sequences of $P_{e_{-} w}, P_{m_{-} w}, P_{e}$ and $n_{e}$ from those of the control variables to see how the total tractive power is distributed among the engine and the motor and to obtain the optimal engine operating points analyzed in the next section.

\section{Optimization of Electric Drive Power Rating}

To optimize the power rating of the electric drive, $P_{m \_ \text {rated }}$, in a full-size engine HEV, the DP algorithm discussed in the previous section is used to calculate the minimum total fuel consumption, which is equivalent to the maximum MPG, during four typical driving cycles (FTP75 Urban, FTP75 Highway, LA92, and SC03) under various values of $P_{m_{-} \text {rated }}$. Then, the sensitivity of the maximum MPG to $P_{m \_r a t e d}$ is analyzed.

Research in [23-27] has proposed an optimization methodology which fixes either the total power rating of the power plants or the acceleration performance of the vehicle and obtains the trend of maximum MPG by increasing the electric drive power rating. Under this methodology, the engine power rating has to be reduced when the electric drive power rating increases. This reduction will potentially worsen the vehicle performances because the smaller engine is the only available power plant to propel the vehicle if the battery SOC drops to its lower bound.

In this section, to ensure that the vehicle performance is not degraded in the optimization process, the power rating of the full-size engine in each of the three IC engine vehicles is kept constant. The performance and fuel economy are further improved with the addition of the electric drive. Therefore, the optimal window of $P_{m_{-} \text {rated }}$, obtained from the sensitivity analysis of the maximum MPG trend with the increasing $P_{m_{-} \text {rated }}$, will be practical for the full-size engine HEV.

The parameters of the DP algorithm used in the optimization of this section are listed in Table 4 . The discrete SOC values expressed in (10) are uniformly distributed within the SOC usable range, and thus the difference between any two adjacent $\mathrm{SOC}$ values, $\mathrm{SOC}_{\Delta}$, is 
kept constant at $5 \times 10^{-4}$. The time interval between two adjacent time points, $\Delta t_{k}$, is one second in all of the four driving cycles, whereas the total time duration, $N$, is different in different driving cycles.

For hybridization of each IC engine vehicle with each of the electric drive power rating values listed in Table 3, the maximum MPG during each driving cycle and the average maximum MPG of the four driving cycles are calculated and plotted in Figure 2. The maximum MPG of each IC engine vehicle without the electric drive, i.e., $P_{m \_r a t e d}=0 \mathrm{~kW}$, is also calculated and plotted for comparison and analysis.

Table 4. Parameters of the DP algorithm.

\begin{tabular}{cc}
\hline Parameter & Value \\
\hline $\mathrm{SOC}_{\text {init }}$ & 0.5 \\
$\mathrm{SOC}_{\text {min }}$ & 0.2 \\
$\mathrm{SOC}_{\text {max }}$ & 0.8 \\
$\mathrm{SOC}_{\Delta}$ & $5 \times 10^{-4}$ \\
$\Delta t_{k}$ & $1 \mathrm{~s}$ \\
$i_{m}$ & 1201 \\
$j_{m}$ & (for Corolla 2019 and Camry 2016) \\
\hline
\end{tabular}

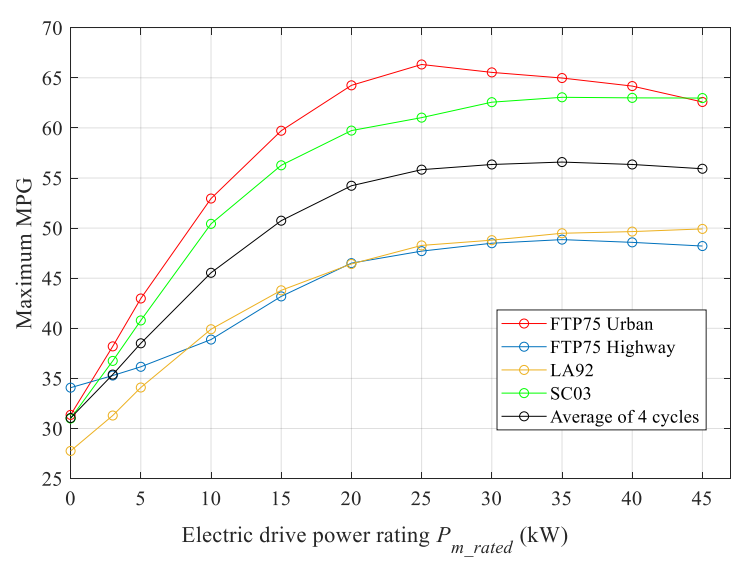

(a)

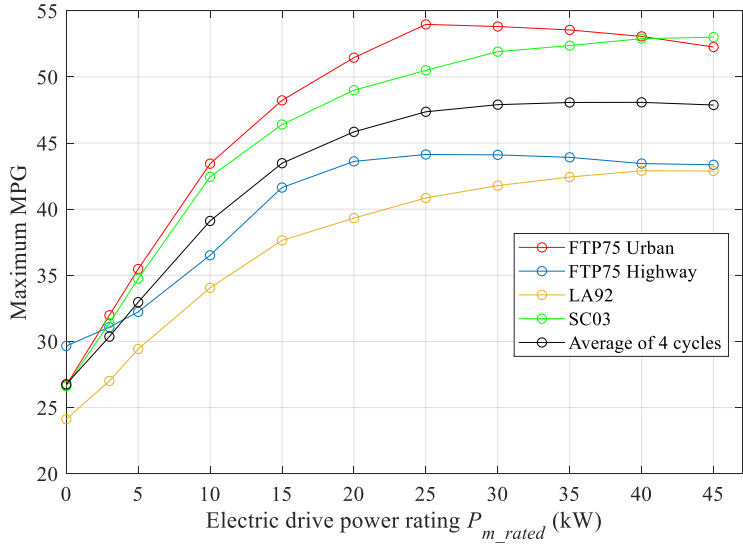

(b)

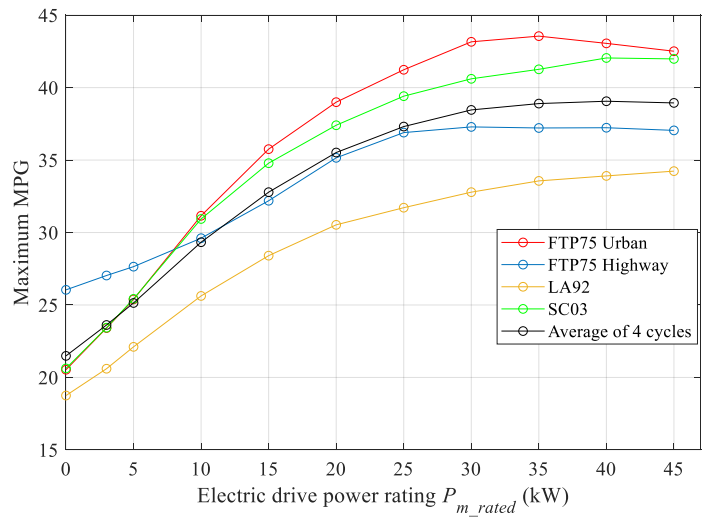

(c)

Figure 2. Maximum MPG versus electric drive power rating in typical driving cycles for hybridization of three typical vehicles: (a) Toyota Corolla 2019; (b) Toyota Camry 2016; (c) Chrysler 3002016.

It is shown in Figure 2 that a vehicle with large mass and high engine power rating (e.g., Chrysler 300 2016) has lower maximum MPG than that with small mass and low engine power rating (e.g., Toyota Corolla 2019) after hybridized with electric drives of the same power rating. However, Figure 2 shows that all the three vehicles during all 
the four driving cycles have the similar trend of sensitivity of MPG to the electric drive power rating $P_{m_{-} \text {rated }}$. Specifically, the maximum MPG starts to increase rapidly as $P_{m_{-} \text {rated }}$ increases from $0 \mathrm{~kW}$ to $10 \mathrm{~kW}$, which means the fuel economy is significantly improved with the help of the electric drive. As $P_{m_{-} \text {rated }}$ keeps on increasing from $10 \mathrm{~kW}$ to $30 \mathrm{~kW}$, the rate of increase in the maximum MPG is still positive and significant but starts to decline because the effect of fuel economy improvement is partially offset by the increasing resistance brought by the additional mass of the electric drive. After $P_{m_{-} \text {rated }}$ exceeds $30 \mathrm{~kW}$, the maximum MPG shows negligible improvement or even starts to decrease as $P_{m \_ \text {rated }}$ increases, which indicates that there is little room for further improvement on the fuel economy, whereas the significant mass increase of the electric drive starts to dominate the MPG trend. Although for different vehicles and during different driving cycles, there are minor differences in the $P_{m \_}$rated value where the maximum MPG reaches its peak and starts to decline, the differences do not play a significant role in the optimization of $P_{m \_r a t e d}$. This is because the additional cost brought by the increase of $P_{m_{-} \text {rated }}$ overwhelms the little, if any, improvement on the fuel economy after $P_{m \_ \text {rated }}$ exceeds $30 \mathrm{~kW}$. Therefore, the upper bound of the optimal window of $P_{m \_r a t e d}$ is determined to be $30 \mathrm{~kW}$, and the lower bound of this window is determined to be $10 \mathrm{~kW}$ because $10 \mathrm{~kW}$ is the upper limit of $P_{m_{-} \text {rated }}$ with the largest rate of increase in MPG. This optimal window of $P_{m_{-} \text {rated }}$ between $10 \mathrm{~kW}$ and $30 \mathrm{~kW}$ is universal regardless of vehicle mass, engine power rating and driving cycle, i.e., it is applicable to all the vehicles with different masses and engine power ratings during all the driving cycles, as illustrated in Figure 2. Therefore, it is possible to produce the same motor-battery package for all different sizes of passenger cars. For example, if the $30 \mathrm{~kW}$ electric drive package is produced for the purpose of optimizing fuel economy, it will be suitable for hybridizing all passenger cars, which will significantly decrease the production cost of the electric drive.

The MPG trends shown in Figure 2 can be also explained from the perspective of the distribution of operating points of the engine in the fuel consumption map. Here, each operating point of the engine refers to a set of the engine speed $n_{e}$ and the engine output power $P_{e}$ at a certain time point in the driving cycle. For example, for the hybridization of Toyota Corolla 2019 during the FTP75 Highway driving cycle, the engine operating points, overlapping the fuel consumption map with various $P_{m_{-} \text {rated }}$ values, are shown in Figure 3 . The operating points in Figure 3 are classified into seven operating modes (hybrid traction, engine-alone traction, charging battery from engine, motor-alone traction, regenerative braking alone, hybrid braking, and mechanical braking alone), which determine the flow direction of motor power $P_{m}$ and load power $P_{l}$ at each operating point, as shown in Table 5. For load power $P_{l}$, positive power means traction, and negative power means braking. For motor power $P_{m}$, positive power means the battery is discharged so that the motor provides propulsion force to the vehicle, and negative power means the battery is charged so that the motor provides regenerative braking force to the vehicle. For engine power $P_{e}$, positive power means the engine provides propulsion force to the vehicle, and zero power means the engine is shut down. $P_{e}$ cannot be negative because the engine cannot be used for regenerative braking purpose. Thus, mechanical braking power $P_{b}$ is needed for braking if the motor cannot supply sufficient braking power to meet the braking demand of the vehicle load. 


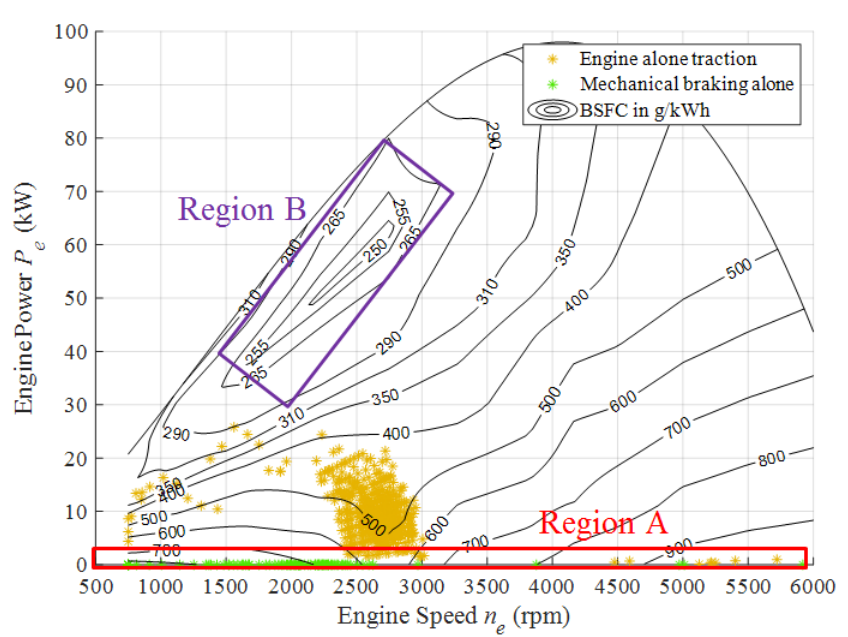

(a)

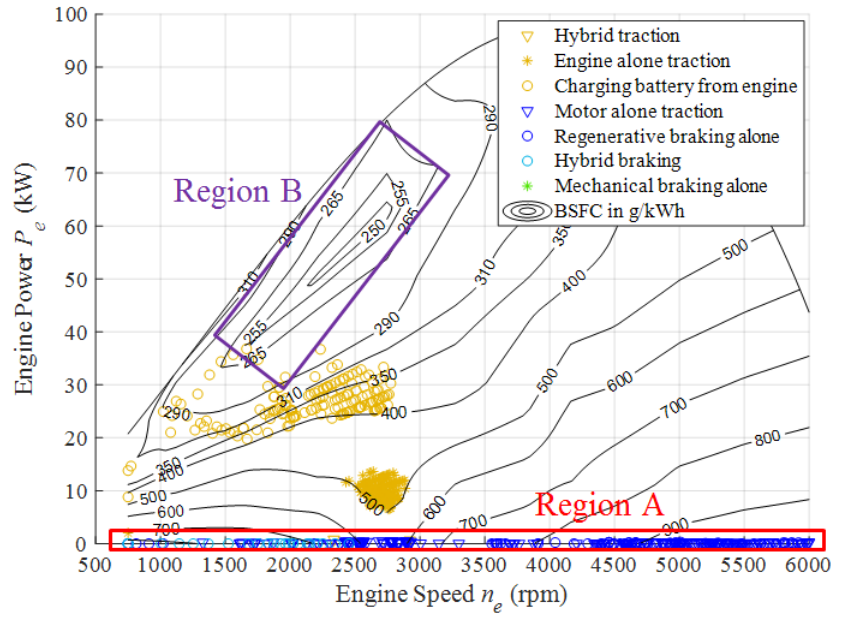

(b)

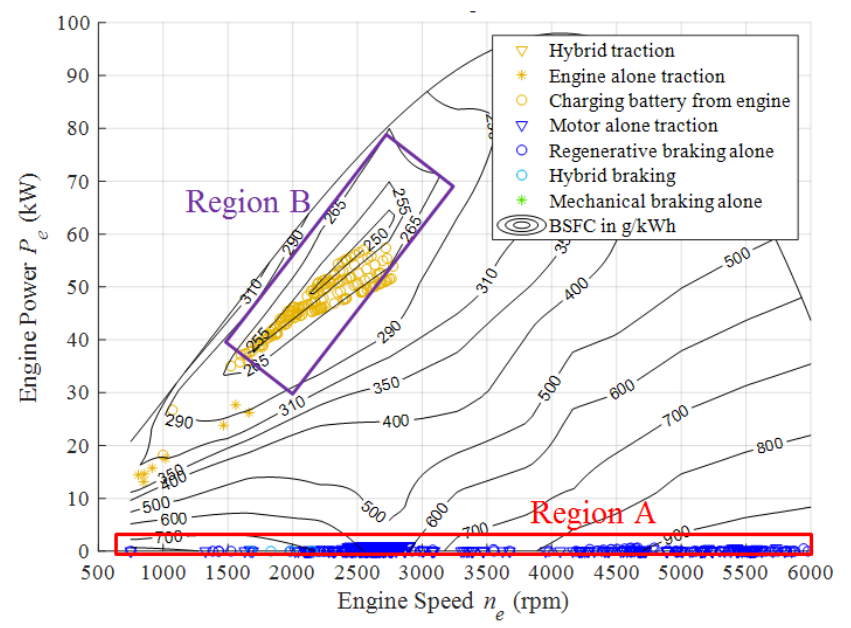

(c)

Figure 3. Optimal engine operating points overlapping the fuel consumption map [1,2] under various operating modes during the FTP75 Highway driving cycle for hybridization of Toyota Corolla 2019 with three $P_{m_{-} \text {rated }}$ values: $(\mathbf{a}) P_{m_{-} \text {rated }}=0 \mathrm{~kW}$; (b) $P_{m \_ \text {rated }}=10 \mathrm{~kW}$; (c) $P_{m \_ \text {rated }}=30 \mathrm{~kW}$.

Table 5. Polarities of powers of motor, engine and load in each operating modes.

\begin{tabular}{cc}
\hline Operating Modes & Polarities of Powers \\
\hline Hybrid traction & $P_{e}>0, P_{m}>0, P_{l}>0$ \\
Engine-alone traction & $P_{e}>0, P_{m}=0, P_{l}>0$ \\
Charging battery from engine & $P_{e}>0, P_{m}<0, P_{l}>0$ \\
Motor-alone traction & $P_{e}=0, P_{m}>0, P_{l}>0$ \\
Regenerative braking alone & $P_{e}=0, P_{m}<0, P_{l}<0, P_{b}=0$ \\
Hybrid braking & $P_{e}=0, P_{m}<0, P_{l}<0, P_{b}<0$ \\
Mechanical braking alone & $P_{e}=0, P_{m}=0, P_{l}<0, P_{b}<0$ \\
\hline
\end{tabular}

In Figure 3 a with $P_{m \_r a t e d}=0 \mathrm{~kW}$, most operating points of the engine lie in the region with significant engine power and high BSFC. According to (9), the fuel consumption $F_{c}$ is large, leading to poor fuel economy. The reason for this undesirable point distribution is that the absence of the electric drive forces the engine power to follow the load power which usually corresponds to points in the fuel consuming region of the map.

To improve the fuel economy, the engine operating points should move away from this fuel consuming region. According to (9), this can be accomplished by either lowering the points towards the region with negligible engine power (Region A), or lifting the points towards the region with low BSFC (Region B). In Region A, most of the operating points 
are under the motor-alone traction mode or the regenerative braking mode because the negligible engine power is insufficient to meet the load power requirement. In Region B, the operating points are under the charging battery from engine mode because the engine power exceeds the load power requirement. Thus, the electric drive is needed in both desirable regions to let the motor power offset the power gap between the engine and the load. The larger rated power $P_{m_{-} \text {rated }}$ the electric drive has, the more motor power it can deliver to offset the power gap, and thus the more operating points it can move towards the two desirable regions, leading to better fuel economy. This principle is shown in Figure $3 b, c$.

With $P_{m \_ \text {rated }}=10 \mathrm{~kW}$ in Figure $3 \mathrm{~b}$, all the lowered operating points lie in Region A, leading to significant MPG improvement. Whereas, most of the lifted operating points are only closer to but do not lie in Region B, and a small portion of the operating points still stay in the fuel consuming region, indicating that there is still some room for further improvement on MPG. With $P_{m_{-} \text {rated }}=30 \mathrm{~kW}$ in Figure $3 \mathrm{c}$, almost all the operating points are moved into either Region A or Region B, indicating that the MPG is close to its peak value shown in Figure 2, and there is little room for further improvement on MPG if $P_{m_{-} \text {rated }}$ keeps on increasing. Similar trends in the distribution of engine operating points can also be seen for the other driving cycles. Therefore, we can conclude that the optimal window of the electric drive power rating is from $10 \mathrm{~kW}$ to $30 \mathrm{~kW}$.

The independence of the optimal window of the electric drive power rating from vehicle mass and engine power rating can be explained from the distribution of operating points of the vehicle load with respect to the power-speed characteristics of the motor. Here, each operating point of the vehicle load refers to a set of the vehicle speed $V$ and the load power $P_{l}$ on the driving wheels at a certain time point in a driving cycle. For example, for each of the three IC engine vehicles without the electric drive, the distribution of the load operating points during the FTP75 Urban driving cycle with respect to the power-speed characteristics of the $10 \mathrm{~kW}$ rated motor and of the $30-\mathrm{kW}$-rated motor are shown in Figure 4. To make the comparisons between the load power and the motor power more convenient, the motor power-speed characteristics in Figure 4 are also transmitted onto the driving wheels.

Note that the engine traction mode in Figure 4 is divided into two submodes, one with full-linkage of the engine to the transmission and another with semi-linkage of the engine to the transmission. The engine usually operates in the full-linkage submode, where almost all of the engine power can be transmitted onto the driving wheels with high efficiency. However, the engine must switch to the semi-linkage submode if the speed of the engine operating in the full-linkage submode falls below the minimum permissible speed of the engine. This usually happens when the vehicle speed is very low. The semi-linkage submode will lead to low efficiency of the engine power transmission because there is a significant friction between the engine shaft and the transmission gearbox if they are only partially linked.

Figure 4 a shows that the $30-\mathrm{kW}$-rated motor has the capacity to supply all the load powers of a compact vehicle like Toyota Corolla 2019. As the vehicle mass increases, the load powers also increase, as shown in Figure $4 \mathrm{~b}, \mathrm{c}$ for a medium-sized vehicle like Toyota Camry 2016 and for a large-sized vehicle like Chrysler 3002016 . However, the 30-kWrated motor can still meet most of the load power demands for both heavier vehicles. Furthermore, for all the three vehicles, the 30-kW-rated motor can supply the powers of all the loads at which the engine has to operate in the semi-linkage submode. This means the 30-kW-rated motor alone can be used for propulsion to prevent the engine from inefficiently operating in the semi-linkage submode, which can significantly help improve the fuel efficiency. On the other hand, there are few or no load operating points lying outside the power range of the $30-\mathrm{kW}$-rated motor, indicating that there will be little or no further improvement on meeting load power demands as the motor power rating keeps on increasing beyond $30 \mathrm{~kW}$. This explains why $30 \mathrm{~kW}$ is the universal upper bound of the optimal window of the electric drive power rating. 


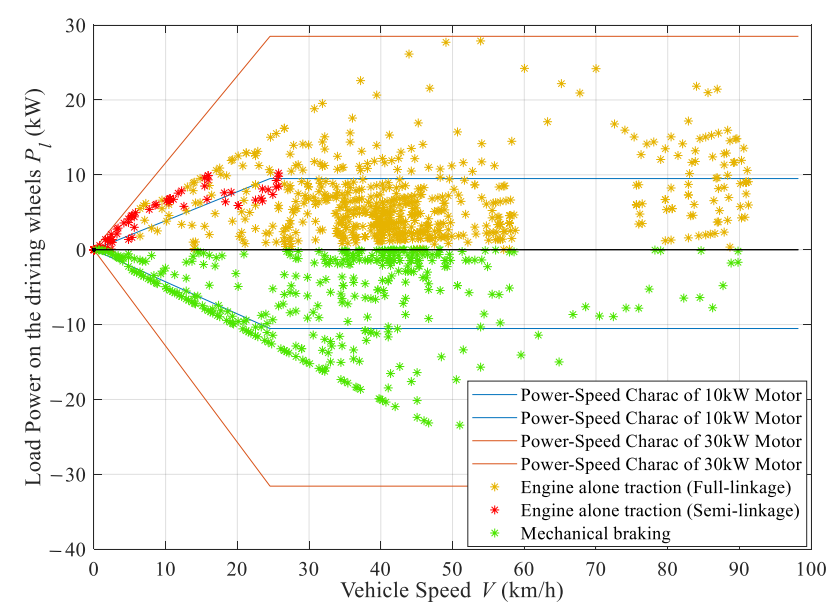

(a)

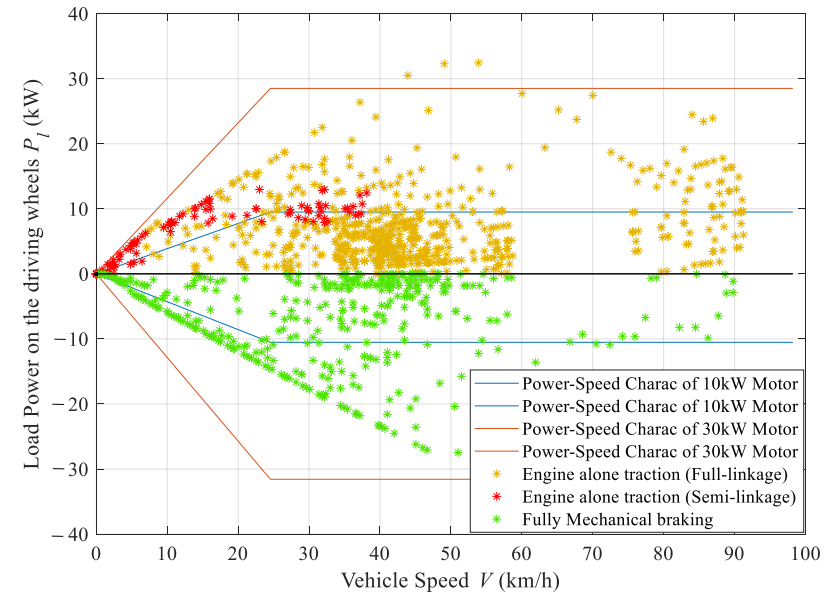

(b)

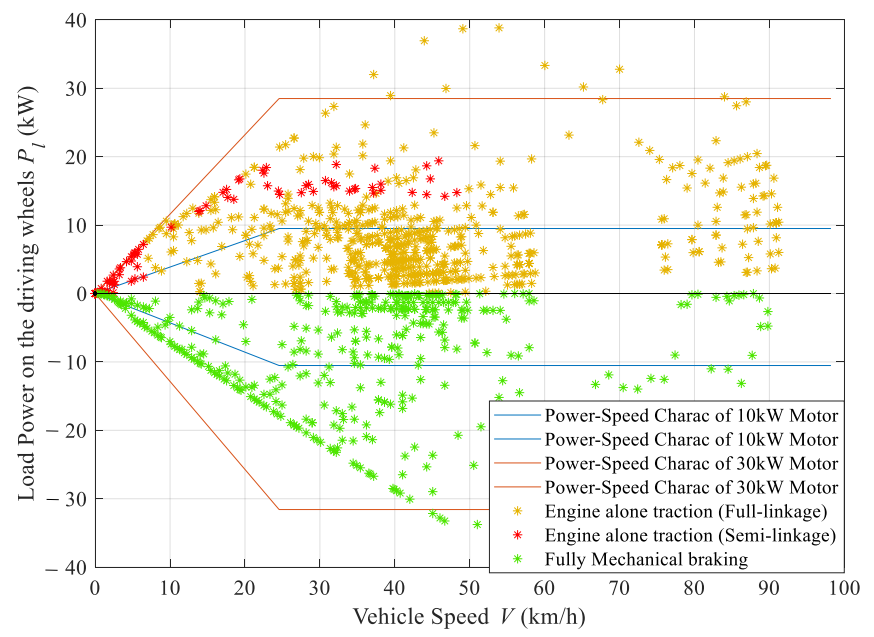

(c)

Figure 4. Load operating points during the FTP75 Urban driving cycle with respect to the power-speed characteristics of the $10 \mathrm{~kW}$ rated motor and of the 30-kW-rated motor for three typical IC engine vehicles: (a) Toyota Corolla 2019; (b) Toyota Camry 2016; (c) Chrysler 3002016.

It is also shown in Figure 4 that for all the three vehicles, the density of load operating points within the power range of the $10 \mathrm{~kW}$ rated motor is significantly higher than that of the points beyond $10 \mathrm{~kW}$ rated motor power range. Therefore, the capability of meeting load power demands can be rapidly enhanced as the motor power rating increases from 0 to $10 \mathrm{~kW}$, whereas the rate of this enhancement slows down as the motor power rating goes beyond $10 \mathrm{~kW}$. This explains why $10 \mathrm{~kW}$ is the universal lower bound of the optimal window of the electric drive power rating.

\section{Comparison with Commercially Available Vehicles}

To demonstrate the advantages of the full-size engine HEVs over IC engine vehicles and commercially available HEVs, the fuel economy, acceleration performance, cost of power plants and cost payback mileage of the full-size engine HEVs are compared with those of Toyota Corolla 2019, an IC engine vehicle without hybridization, and with those of 2019 Toyota Prius, a commercially available HEV consisting of a large electric drive and a relatively small IC engine.

A model of Corolla-based full-size engine HEV is constructed by adding a relatively small electric drive in parallel to the full-size $(98 \mathrm{~kW})$ engine of Corolla 2019. Because $10 \mathrm{~kW}$ and $30 \mathrm{~kW}$ are the lower and upper bounds of the optimal window of the electric 
drive power rating $P_{m \_ \text {rated }}$, we make two models of the Corolla-based full-size engine HEVs, one with $P_{m \_ \text {rated }}=10 \mathrm{~kW}$ and another with $P_{m_{-} \text {rated }}=30 \mathrm{~kW}$.

Using the DP algorithm introduced in this paper, we calculate the maximum MPGs of the two HEV models during FTP 75 Urban and FTP 75 Highway driving cycles, and compare them with those of the Corolla 2019. To obtain the overall fuel economy during the two driving cycles, a combined MPG taking $55 \%$ of the urban MPG and $45 \%$ of the highway MPG is also calculated and compared. To make fair comparisons under the same conditions, the maximum MPGs of the Corolla 2019 are also calculated using the same DP algorithm, rather than directly copied from its commercial MPG data. The maximum MPGs of the three vehicles are listed in Table 6, which shows that both full-size engine HEVs have significantly better fuel economy than the Corolla 2019.

Table 6. Maximum MPGs of Corolla-based vehicles.

\begin{tabular}{cccc}
\hline Vehicles & Urban & Highway & Combined \\
\hline Corolla 2019 & 31.35 & 34.07 & 32.57 \\
HEV $\left(P_{m_{-} \text {rated }}=10 \mathrm{~kW}\right)$ & 52.95 & 38.88 & 46.62 \\
HEV $\left(P_{m_{-} \text {rated }}=30 \mathrm{~kW}\right)$ & 65.54 & 48.49 & 57.87 \\
\hline
\end{tabular}

The acceleration performance is specified in this study as the acceleration time for the vehicle speed from 0 to $60 \mathrm{mph}(26.8 \mathrm{~m} / \mathrm{s})$ on a flat road, which can be calculated as

$$
t_{a}=\int_{V_{1}}^{V_{2}} \frac{M \delta}{\frac{T_{e \_-w}+T_{m \_} w}{r_{d}}-M g f_{r}-\frac{1}{2} \rho_{a} C_{D} A_{f} V^{2}} d V
$$

where $V_{1}=0, V_{2}=26.8 \mathrm{~m} / \mathrm{s}, T_{e_{\_} w}$ and $T_{m_{\_} w}$ are the engine torque and the motor torque transmitted onto the driving wheels, respectively.

Using (15), we can calculate the acceleration time from 0 to $60 \mathrm{mph}$ for the three vehicles, as listed in Table 7, which shows that both full-size engine HEVs have better acceleration performance than the Corolla 2019.

Table 7. Acceleration time from 0 to $60 \mathrm{mph}$ for Corolla-based vehicles.

\begin{tabular}{cc}
\hline Vehicles & Acceleration Time (s) \\
\hline Corolla 2019 & 7.53 \\
HEV $\left(P_{m_{-} \text {rated }}=10 \mathrm{~kW}\right)$ & 7.14 \\
HEV $\left(P_{m_{-} \text {rated }}=30 \mathrm{~kW}\right)$ & 6.58 \\
\hline
\end{tabular}

The Toyota Prius 2019 is a series-parallel HEV whose maximum MPGs cannot be calculated using the DP algorithm introduced in this paper because this DP algorithm can only be used to calculate the maximum MPGs of parallel HEVs. To estimate the fuel economy of the Prius 2019 under optimal control, an equivalent parallel HEV model (Modified Prius) is made. The electric drive power rating $P_{m \_ \text {rated }}$ of the Modified Prius is designed to be the same as the Prius 2019, which is $53 \mathrm{~kW}$, so that the Modified Prius will have roughly the same weight as Prius 2019, and its initial cost will also be close to Prius 2019. The reason for this design is that the fuel economy is affected by the vehicle weight, and the initial cost is largely determined by $P_{m_{-} \text {rated }}$ because the price per $\mathrm{kW}$ of the motor is much higher than that of the engine. The engine power rating of the Modified Prius is determined to be $31 \mathrm{~kW}$, which ensures that the Modified Prius has the same acceleration performance (acceleration time from 0 to $60 \mathrm{mph}$ ) as the Prius 2019.

To construct full-size engine HEV models based on the Prius 2019, an IC engine vehicle model (Engine-only Prius) is made first. The engine power rating of the Engineonly Prius is determined to be $73 \mathrm{~kW}$, which ensures that the Engine-only Prius has the same performance (acceleration time from 0 to $60 \mathrm{mph}$ ) as the Prius 2019. Then, a relatively small electric drive is added in parallel to the full-size engine of the Engine-only Prius, 
making a Prius-based full-size engine HEV. Similar to the Corolla-based HEVs, two models of the Prius-based full-size engine HEVs are made, one with $P_{m_{-} \text {rated }}=10 \mathrm{~kW}$ and another with $P_{m \_}$rated $=30 \mathrm{~kW}$.

The maximum MPGs of all the Prius-based vehicles are listed in Table 8. They are all calculated using the DP algorithm introduced in this paper, except for those of the Prius 2019, which is estimated to be lower than those of the Modified Prius. The reason for such estimation is that the Prius 2019 has a much larger engine $(71 \mathrm{~kW})$ than the Modified Prius $(31 \mathrm{~kW})$.

Table 8. Maximum MPGs of Prius-based vehicles.

\begin{tabular}{cccc}
\hline Vehicles & Urban & Highway & Combined \\
\hline Engine-only Prius & 35.75 & 36.57 & 36.11 \\
HEV $\left(P_{\text {m_rated }}=10 \mathrm{~kW}\right)$ & 57.77 & 46.36 & 52.63 \\
HEV $\left(P_{m_{-} \text {rated }}=30 \mathrm{~kW}\right)$ & 71.40 & 52.07 & 62.70 \\
Modified Prius & 73.31 & 58.91 & 66.83 \\
${\text { Prius } 2019^{1}}^{1}$ & $<73.31$ & $<58.91$ & $<66.83$ \\
\hline
\end{tabular}

${ }^{1}$ Maximum MPGs of the Prius 2019 are estimated based on those of the Modified Prius.

To compare the costs of power plants for all the Prius-based vehicles, we assume that the average prices of the induction motor, the IC engine, and the battery pack are $\$ 110$ per $\mathrm{kW}, \$ 35$ per $\mathrm{kW}$, and $\$ 137$ per $\mathrm{kWh}$, respectively $[2,28,29]$. To calculate the cost payback mileages, we assume that the price of gasoline is $\$ 4$ per gallon [2]. The costs of power plants and payback mileages for the Prius-based vehicles are listed in Table 9.

Table 9. Costs of power plants and cost payback mileages for Prius-based vehicles.

\begin{tabular}{ccc}
\hline Vehicles & Cost $\mathbf{( \$ )}$ & Payback (mile) \\
\hline Engine-only Prius & 2553 & NaN \\
HEV $\left(P_{m_{-} \text {rated }}=10 \mathrm{~kW}\right)$ & 3699 & 32,990 \\
HEV $\left(P_{m_{-} \text {rated }}=30 \mathrm{~kW}\right)$ & 5993 & 73,249 \\
Modified Prius & 7163 & 90,562 \\
${\text { Prius } 2019^{1}}^{1}$ & 8563 & $>118,065$
\end{tabular}

${ }^{1}$ Payback mileage of the Prius 2019 is estimated to be longer than 118 k miles, based on the Prius 2019's cost of power plants and the Modified Prius's fuel economy.

Table 8 shows both the full-size engine HEVs have significantly better fuel economy than the Engine-only Prius, and the fuel economy of the full-size engine HEV with $P_{m_{-} \text {rated }}=30 \mathrm{~kW}$ is close to that of the Modified Prius and may be better than that of the Prius 2019. In the meantime, the costs of power plants in both full-size engine HEVs are significantly lower than those in the Modified Prius and the Prius 2019, as shown in Table 9. Therefore, the cost payback mileages of both full-size engine HEVs are significantly shorter than those of the Modified Prius and the Prius 2019, as shown in Table 9.

The acceleration time from 0 to $60 \mathrm{mph}$ for all the Prius-based vehicles are listed in Table 10, which shows that both full-size engine HEVs have better acceleration performance than the Engine-only Prius, the Modified Prius, and the Prius 2019. Note that the acceleration time for the Modified Prius and the Engine-only Prius is by design the same as that for the Prius 2019, which is found on [30].

Table 10. Acceleration time from 0 to $60 \mathrm{mph}$ for Prius-based vehicles.

\begin{tabular}{cc}
\hline Vehicles & Acceleration Time (s) \\
\hline Engine-only Prius & 9.79 \\
HEV $\left(P_{m_{-} \text {rated }}=10 \mathrm{~kW}\right)$ & 9.11 \\
HEV $\left(P_{m_{-} \text {rated }}=30 \mathrm{~kW}\right)$ & 7.61 \\
Modified Prius & 9.79 \\
Prius 2019 & 9.79 \\
\hline
\end{tabular}




\section{Conclusions}

This paper proposed a universally optimized parallel HEV drivetrain, which uses the full-size IC engine as the primary power plant to ensure that the vehicle performance and the travel range of the hybridized vehicle are at least the same as the original IC engine vehicle. To improve the fuel economy and performance, an optimal size electric drive, including an electric motor, a battery bank, and power electronic converters, was added in parallel with this full-size engine.

Three commercially available IC engine vehicles with different curb masses and engine power ratings were chosen as representative passenger cars on the market. The original power ratings of the engines were kept for this hybridization.

To find the optimal power rating of the electric drive, we developed a DP algorithm to calculate the maximum MPG and find the optimal sequence of the engine operating points during the driving cycle. The optimality of the solution obtained from the algorithm was guaranteed by selecting the battery $\mathrm{SOC}$ and the number of gears in the engine transmission as the control variables of the algorithm.

The optimal window of electric drive power rating was found to be between $10 \mathrm{~kW}$ and $30 \mathrm{~kW}$. This was shown to be independent of IC engine power rating and vehicle mass by analyzing the sensitivity of the maximum MPG to the electric drive power rating during each test driving cycle. Therefore, all passenger cars, regardless of their masses and engine sizes, can be universally optimally hybridized with one size of electric drive packages, further reducing the hybridization cost. The sensitivity of the maximum MPG to the electric drive power rating and the universality of the optimal window were further explained in terms of the distribution of the optimal engine operating points in the engine fuel consumption map and the distribution of the load operating points with respect to the power-speed profiles of the motor.

To show the advantages of the full-size engine HEVs proposed in this paper over the conventional IC-engine based vehicles and commercially available HEVs, comparisons were made with two types of popular passenger cars for fuel economy, acceleration performance, cost of power plants and cost payback mileage. The proposed full-size engine HEV has significantly better fuel economy as well as better performance than the equivalent IC engine vehicle. This HEV was also shown to have better performance and shorter cost payback than conventional HEVs.

Further research may be done to find a real-time control strategy for the full-size engine HEV. This will be independent of the driving cycle.

Author Contributions: Conceptualization, L.L. and M.E.; methodology, Z.H. and L.L.; software, Z.H.; validation, Z.H., R.T.M. and M.E.; formal analysis, Z.H.; investigation, R.T.M.; resources, L.L., R.T.M. and M.E.; data curation, Z.H.; writing—original draft preparation, Z.H.; writing—review and editing, Z.H., R.T.M. and M.E.; visualization, Z.H.; supervision, M.E.; project administration, M.E.; funding acquisition, N/A. All authors have read and agreed to the published version of the manuscript.

Funding: This research received no external funding.

Institutional Review Board Statement: Not applicable.

Informed Consent Statement: Not applicable.

Data Availability Statement: Publicly available datasets were analyzed in this study. The data can be found here: [12-14,30].

Conflicts of Interest: The authors declare no conflict of interest.

\section{References}

1. Ehsani, M.; Gao, Y.; Longo, S.; Ebrahimi, K. Modern Electric, Hybrid Electric, and Fuel Cell Vehicles_Fundamentals, Theory, and Design, 3rd ed.; CRC Press: Boca Raton, FL, USA, 2018; pp. 1-16.

2. Lai, L. A Development of Design and Control Methodology for Next Generation Parallel Hybrid Electric Vehicle. Ph.D. Thesis, Texas A\&M University, College Station, TX, USA, 2012.

3. Car and Driver. Available online: https://www.caranddriver.com/chevrolet/bolt-ev (accessed on 5 January 2021). 
4. Reyes, J.; Parsons, R.; Hoemsen, R. Winter happens: The effect of ambient temperature on the travel range of electric vehicles. IEEE Trans. Veh. Technol. 2016, 65, 4016-4022. [CrossRef]

5. Lin, C.; Peng, H.; Grizzle, J.; Kang, J. Power management strategy for a parallel hybrid electric truck. IEEE Trans. Control Syst. Technol. 2003, 11, 839-849.

6. Cieslik, W.; Zawartowski, J.; Fuc, P. The Impact of the Drive Mode of a Hybrid Drive System on the Share of Electric Mode in the RDC Test; SAE Technical Paper; SAE Powertrains, Fuels \& Lubricants Meeting: Krakow, Poland, 2020. [CrossRef]

7. Pielecha, I.; Cieślik, W.; Merkisz, J. Analysis of the electric drive mode use and energy flow in hybrid drives of SUVs in urban and extra-urban traffic conditions. J. Mech. Sci. Technol. 2019, 33, 5043-5050. [CrossRef]

8. Wirasingha, S.; Schofield, N.; Emadi, A. Plug-in hybrid electric vehicle developments in the US: Trends, barriers, and economic feasibility. In Proceedings of the 2008 IEEE Vehicle Power and Propulsion Conference, Harbin, China, 3-5 September 2008.

9. Gao, Y.; Ehsani, M. Design and control methodology of plug-in hybrid electric vehicles. IEEE Trans. Ind. Electron. 2010, 57, 633-640.

10. Hardman, S.; Plotz, P.; Tal, G.; Axsen, J.; Figenbaum, E.; Karlsson, S. Exploring the Role of Plug-in Hybrid Electric Vehicles in Electrifying Passenger Transportation. Available online: https:/ / escholarship.org/uc/item/3w53q2h9\#author (accessed on 17 October 2021).

11. Peterson, S.; Whitacre, J.; Apt, J. The economics of using plug-in hybrid electric vehicle battery packs for grid storage. J. Power Source 2010, 195, 2377-2384. [CrossRef]

12. Car and Driver. Available online: https://www.caranddriver.com/toyota/corolla/specs/2019/toyota_corolla_toyota-corolla_20 19/399278 (accessed on 17 October 2021).

13. New-Cars. Available online: http:/ / www.new-cars.com/2016/toyota/specs/camry.html (accessed on 17 October 2021).

14. New-Cars. Available online: http://www.new-cars.com/2016/chrysler/specs/300.html (accessed on 17 October 2021).

15. Kelly, K.J.; Mihalic, M.; Zolot, M. Battery usage and thermal performance of the Toyota prius and Honda insight during chassis dynamometer testing. In Proceedings of the 17th Annual Battery Conference on Applications and Advances, Long Beach, CA, USA, 18 January 2002.

16. Kuhn, B.; Pitel, G.; Krein, P. Electrical properties and equalization of lithium-ion cells in automotive application. In Proceedings of the IEEE Vehicle Power and Propulsion Conference, Chicago, IL, USA, 7-9 September 2005.

17. Valoen, L.; Shoesmith, M. The effect of PHEV and HEV duty cycles on battery and battery pack performance. In Proceedings of the Plug-In Hybrid Electric Vehicle 2007 Conference, Winnipeg, MB, Canada, 1-2 November 2007.

18. Zaghib, K.; Charest, P.; Guerfi, A.; Shim, J.; Perier, M.; Striebel, K. Safe li-ion polymer batteries for HEV applications. J. Power Source 2004, 134, 124-129. [CrossRef]

19. Affanni, A.; Bellini, A.; Franceschini, G.; Guglielmi, P.; Tassoni, C. Battery choice and management for new-generation electric vehicles. IEEE Trans. Ind. Electron. 2005, 52, 1343-1349. [CrossRef]

20. Bertsekas, D.P. Dynamic Programming and Optimal Control, 3rd ed.; Athena Scientific: Belmont, TN, USA, 2005 ; pp. 18-34.

21. Cormen, T.H.; Leiserson, C.E.; Rivest, R.L.; Stein, C. Introduction to Algorithms, 3rd ed.; The MIT Press: Cambridge, MA, USA, 2009; pp. 359-413.

22. Perez, L.V.; Bossio, G.R.; Moitre, D.; Garcia, G.O. Optimization of power management in an hybrid electric vehicle using dynamic programming. Math. Comput. Simul. 2006, 73, 244-254. [CrossRef]

23. Zoelch, U.; Schroeder, D. Dynamic optimization method for design and rating of the components of a hybrid vehicle. Int. J. Veh. Des. 1998, 19, 1-13.

24. Varesi, K.; Radan, A. A novel methodology proposed for optimizing the degree of hybridization in parallel HEVs using genetic algorithm. WASET 2011, 5, 915-920.

25. Vinot, E.; Trigui, R.; Jcanneret, B.; Scordia, J.; Badin, F. HEVs comparison and components sizing using dynamic programming. In Proceedings of the 2007 IEEE Vehicle Power and Propulsion Conference, Arlington, TX, USA, 9-12 September 2007.

26. Lukic, S.M.; Emadi, A. Effects of drivetrain hybridization on fuel economy and dynamic performance of parallel hybrid electric vehicles. IEEE Trans. Veh. Technol. 2004, 53, 385-389. [CrossRef]

27. Kim, M.; Peng, H. Power management and design optimization of fuel cell/battery hybrid vehicles. J. Power Source 2007, 165, 819-832. [CrossRef]

28. Lowe, M.; Tokuoka, S.; Trigg, T.; Gereffi, G. Lithium-Ion Batteries for Electric Vehicles: The U.S. Value Chain; Duke University CGGC: Durham, NC, USA, 2010.

29. Renewable Energy World. Available online: https://www.renewableenergyworld.com/storage/annual-survey-finds-batteryprices-dropped-13-in-2020/\#gref (accessed on 5 October 2021).

30. Zero To 60 Times. Available online: https://www.zeroto60times.com/vehicle-make/toyota-0-60-mph-times / ?yearMin=2019 \&yearMax=2020\&engineType \%5B\%5D=Gas+Electric+Hybrid (accessed on 5 January 2021). 